Results Of the 31 reports reviewed, 16 (52\%) of children were referred for concerns of physical neglect however there were often concerns regarding other unmet health needs. Following 'neglect medicals', new concerns regarding physical neglect were identified in $16(52 \%)$, emotional neglect in 6 (19\%), medical neglect in $6(19 \%)$, supervision in $5(16 \%)$, nutritional in $4(13 \%)$ and educational neglect in $3(9.6 \%)$ of children. For 11 (35\%) children, referrals were made for ongoing care. One child was admitted acutely. The legal status changed for 16 of the 24 children already known to social care.

Conclusion It is clear that although the majority of assessments done were for physical neglect, other categories of childhood neglect coexist. There is evidence to support further referrals by social care for assessment of children where there are concerns of neglect. Through early identification and intervention, the cumulative harmful effects of neglect can be minimised. This could be achieved via lowering the threshold for neglect medical assessments.

\section{G485 IMPLEMENTING GUIDELINES ON RADIOLOGICAL INVESTIGATIONS OF CHILDREN PRESENTING WITH SUSPECTED PHYSICAL ABUSE - IMPLICATIONS FOR PRACTICE}

L Shekhar, I Lakshminarayana. Paediatrics, The Royal Wolverhampton NHS Trust, Wolverhampton, UK

\subsection{6/archdischild-2020-rcpch.416}

Aim The new guidance on radiological investigations for suspected physical abuse brings clarity on investigations and sets recommendations for good practice. Adherence to this guideline ensures that occult injuries are diagnosed correctly and safeguarding decisions are made promptly and shared with multiagency partners thereby avoiding long hospital stays. However, this poses challenges to the radiology workforce in District General Hospitals as often there is a shortage of paediatric trained radiographers and radiologist.

This project aims to develop systems in place so this guideline is embedded in practice and to ensure compliance of this guideline.

Method A business case was developed to upgrade and improve the current provision of service delivered by the radiology department. A standard operating procedure for skeletal surveys ( SS) was developed. A retrospective audit of all radiological requests for skeletal surveys between April 2018 to September 2019 was completed to inform gaps in services and to implement change.

Results Twenty-five children had skeletal surveys during this period. Forty per cent of children were between 1-6 months of age with $20 \%$ of them being neonates. In over two thirds $(72 \%)$ of cases, SS was acquired within 24 hours and in over half (56\%) of cases reported within 24 hours. In over a quarter of cases $(28 \%)$ the report identified single fractures and in $8 \%$ of cases multiple fractures. Over threequarters of them $(76 \%)$ has repeat skeletal survey and reason for not repeating SS was due to clinical reasons or parents declining consent. A double reporting system where the initial reports completed by the local paediatric radiologist were then reviewed by the tertiary paediatric radiologist was established and up and running well. The average length of inpatient stay was 5 days. Documentation of consent was poor.

Conclusion We have demonstrated good compliance with the guidelines. Collaborative working between radiology and paediatrics has enabled to improve services and the care that we deliver to these vulnerable group of children. A consent form and patient information leaflet have been designed to address the issue of consent.

\section{G487(P) IS CLINICIAN GAZE AND BODY LANGUAGE ASSOCIATED WITH THEIR ABILITY TO IDENTIFY SAFEGUARDING CUES?}

${ }^{1} \mathrm{~A}$ Powell, ${ }^{2} \mathrm{~T}$ Collingwoode-Williams, ${ }^{3} \mathrm{~N}$ Schindler, ${ }^{2} \mathrm{SX}$ Pan, ${ }^{4} \mathrm{C}$ Fertleman. ${ }^{1}$ Medical School, University College London, London, UK; ${ }^{2}$ Department of Computing, Goldsmiths, London, UK; ${ }^{3}$ Paediatrics, Cambridgeshire Community Services NHS Trust, Cambridge, UK; ${ }^{4}$ Paediatrics/Undergraduate Education at UCL Medical School, Whittington Health Trust/ UCL, London, UK

\subsection{6/archdischild-2020-rcpch.417}

Aims Do GPs who undertake a covert child safeguarding virtual reality scenario use empathetic body language and look at the child in a parental consultation?

Methods This study used virtual reality consultations from 'A study of professional awareness using virtual reality: the responsiveness of GPs to child safeguarding cues'. These detail a consultation between a GP and a virtual reality avatar of a father and son. The behaviour of the father towards his son should elicit concern.

This study investigated whether the body language and gaze behaviour of the clinician was associated with their ability to identify safeguarding cues. Body language was measured in terms of head nod, body lean and eye contact, and gaze as the proportion of the consultation in which the clinician was looking at the child.

We conducted follow-up interviews with GP participants 18 months after the original study. These interviews covered their opinions of the study and virtual reality in general.

Consultations from 61 original participants were used, and 12 were interviewed.

Results There was a strong, statistically significant association $(\delta=0.606, \mathrm{p}<0.05)$ between empathetic body language and an ability to identify safeguarding cues. There was a weak, non-significant association $\left(\tau_{\mathrm{b}}=0.202, \mathrm{p}=0.06\right)$ between child-directed gaze and an ability to identify safeguarding cues.

At follow-up interview, some GPs felt that virtual reality was a useful training tool as it was more accessible than traditional training with actors. There was a consensus that the current iteration of the interface was not reactive enough, and that this was a barrier to interaction with the avatar and immersion in the consultation.

Conclusion This study has shown an association between empathetic body language and an ability to identify safeguarding cues within a simulated virtual reality consultation. Future prospective research could help determine why this association exists and if teaching in non-verbal communication skills can help to improve the recognition of safeguarding cues in clinical practice. It has also highlighted the use of virtual reality in paediatric safeguarding training, where child actors cannot be used, due to their age and the sensitivity of the scenario. 